\title{
A Comparative study to assess nutritional assessment of working and non-working parents having children 0-3 years of age at selected area, Ludhiana, Punjab
}

Introduction: Health is a fundamental right of every individual. The factors which influence the growth are heredity, sex, race, nationality, environment such as pre- natal and post-natal, cultural influences, socioeconomic status of family nutrition, climate, season, exercise, hormonal influences.

Aim: The objectives of study were to assess the nutritional status of children (0-3 years) among working and non-working parents to compare the nutritional status of those children.

Method: Quantitative approach was used in the study. Subjects were chosen by simple random sampling technique and sample size was 60. Data was collected by structured questionnaire Pilot study was done on 5 children (age 0-3 years) to check feasibility and practibility of the study. Data collection was done in month of April 2015.

Result: Analysis and interpretation was done according to the objectives of the study. Bar diagrams are used to depict the findings. The present study revealed that majority of children who were assessed for nutritional status were in the age group of 2-3 years and majority of them were males having 1 birth order and age of parents falls under 21-30 years whose occupation of father is private and mother is housewife and education of father is matric/ senior secondary and education of mother is graduate/post graduate and type of family is nuclear.

Conclusion: The present study revealed that majority of children among non-working women were normal and mother's employment leads to $93.3 \%$ normal children and $6.67 \%$ fall under grade I i.e. mild degree of malnutrition.

\section{KEYWORDS: nutritional status, working parents, non-working parents, questionnaire}

\section{Introduction}

Children are the wealth of tomorrow. Take care of them if you wish to have strong India. It was a slogan in 1986. "Health is a fundamental right of every individual. Each and every individual is the citizen of the country. The child's future depends upon the physical, intellectual and emotional growth. Therefore the family, the community and the country as a whole must create conditions to shape the personality of child for useful role in Nation's future. All efforts must be concentrated to secure a happy and prosperous future for blooming flowers [1]. Malnutrition is a major problem especially in developing countries [2]. Malnourished children have lower resistance to infection. They are more likely to die of common childhood ailments. The 2001 census of India shows that $40 \%$ of the population comprises of children between the ages of 5 to 14 year. School children constitute a large pool of children of this group. Infants (0-1 year) constitute $2.92 \%$ of the total population of the India and 1.35 million children born in each year in the world. Presently $13.12 \%$ of population comprises children between the ages of 0-6 years, out of that the male children ( $0-6$ years) are $13.30 \%$ and female children (0-6 years) are $12.92 \%$ [3]. Malnutrition is more common in India. One in every 3 malnourished children in the world lives in India [4]. A hungry and irritated child will not be able to concentrate on studies. On the other hand a well fed child is quite, oriented and seems to do all work Malnutrition is a major problem especially in developing countries. It affects almost 800 million people -205 of all in developing world. Malnourished children have lower resistance to infection [5].They are more likely to die of common childhood ailments like diarrheal diseases, respiratory infection and those who survive frequent illness affect their nutritional status putting them into vicious cycle of recurring sickness, slow growth and diminished learning ability [6]. Along with economic deprivation, cultural factors play a
Rajdeep Kaur ${ }^{1}$, Suraj Mathew², Mandeep Kaur*3

${ }^{1}$ Fortis Hospital Mohali, Punjab, India ${ }^{2}$ M. D. Oswal college of Nursing, Ludhiana, Punjab

${ }^{3}$ Department of Pharmacy Practice ISFCP, Punjab, India

*Author for correspondence:

Kaurm235@gmail.com 
significant role in the health of the population. Child marriage, early motherhood, frequent deliveries, absence of antenatal and postnatal care affects the women health too. Improvement in nutritional status has not kept pace with the reduction in poverty and the current level of malnutrition is unacceptably high. Malnutrition levels are uneven across states. Some middle income states such as Kerala and Tamil Nadu have comparatively better nutritional achievement than higher income states like Maharashtra and Gujarat. Northern states are comparatively better performing states and some of them have even out performed Kerala [7]. Growth refers to an increase in physical size of the whole or any of its parts and can be measured in inches and in centimeters and in pounds or kilograms. It causes a qualitative change in child's body. The factors which influence the growth are heredity, sex, race, nationality, environment such as prenatal and postnatal, cultural influences, socioeconomic status of family nutrition, climate, season, exercise, hormonal influences. Malnutrition in early childhood has serious long term consequences because it impedes motor, sensory, cognitive, social and emotional development [8]. Malnourished children are less likely to perform well in school and more likely to grow into malnourished adults. A hungry and irritated child will not be able to concentrate on studies. On the other hand a well fed child is quite, oriented and seems to do all work proper [9]. According to this explanation, children of working mothers receive less attention and less care, which lead to their lower survival rates. This paper aims at re-examining the relation between maternal employment and child survival in India-one of the largest countries with a relatively high level of infant and child mortality. It examines the nature of the relationship between maternal employment and child mortality and investigates under which conditions a negative relationship between the two might exist $[10,11]$.

\section{Material and Methods}

The research methodology includes strategy to be used to collect and analysis of data to accomplish the research objectives and to test the research hypothesis. This chapter dealt with methodology undertaken to assess the nutritional status of children (0-3 years of age) among working and non-working parents, Ludhiana.

\section{- Research approach}

Keeping in view the objectives of study, research approach chosen for present study was Quantitative approach, a comparative study which was considered to be appropriate in the view of the nature of problem and to accomplish the objectives of study [12].

\section{Research design}

For the fulfilling of the objectives of the present study, non-experimental research design was utilized for collection and analysis of the data as shown in (FIGURE1).

\section{- Independent variables}

Age, gender, birth order, age of parents, occupation of mother, occupation of father, education of mother, education of father, type of family.

\section{- Dependent variables}

Nutritional status of children (0-3 years of age).

\section{Selection and description of field} for study

The study was conducted in Daba village, Ludhiana. It is developing rural area and it was 5 $\mathrm{km}$ away from the Oswal College of nursing. The facilities in the area are sub- centre, dispensary, shops, primary and secondary schools and transport facilities are available.

\section{- Population}

In the study, the target population is comprised of children between age group of 0-3 years among working and non-working parents.

\section{Sample and sampling technique}

Purposive sampling technique was used.

Sample: Children $\mathrm{N}=60$

Children of working parents $=30$

Children of non-working parents $=30$

Following instruments have been used for taking anthropometric measurements.

1. Weighing machine(Krups - Mfd by Doctor Bedi Ram \& Sons (MfG)

2. Flexible steel tape

\section{- Criterion measures:}

Weight for age:

According to Indian Academy of Paediatrics classification four degrees of Malnutrition besides normal were derived:

- $>80 \%$ mean weight for age: Normal

- $70-90 \%$ mean weight for age: I Degree(Mild)

- 60-69\% mean weight for age: II Degree(moderate) 


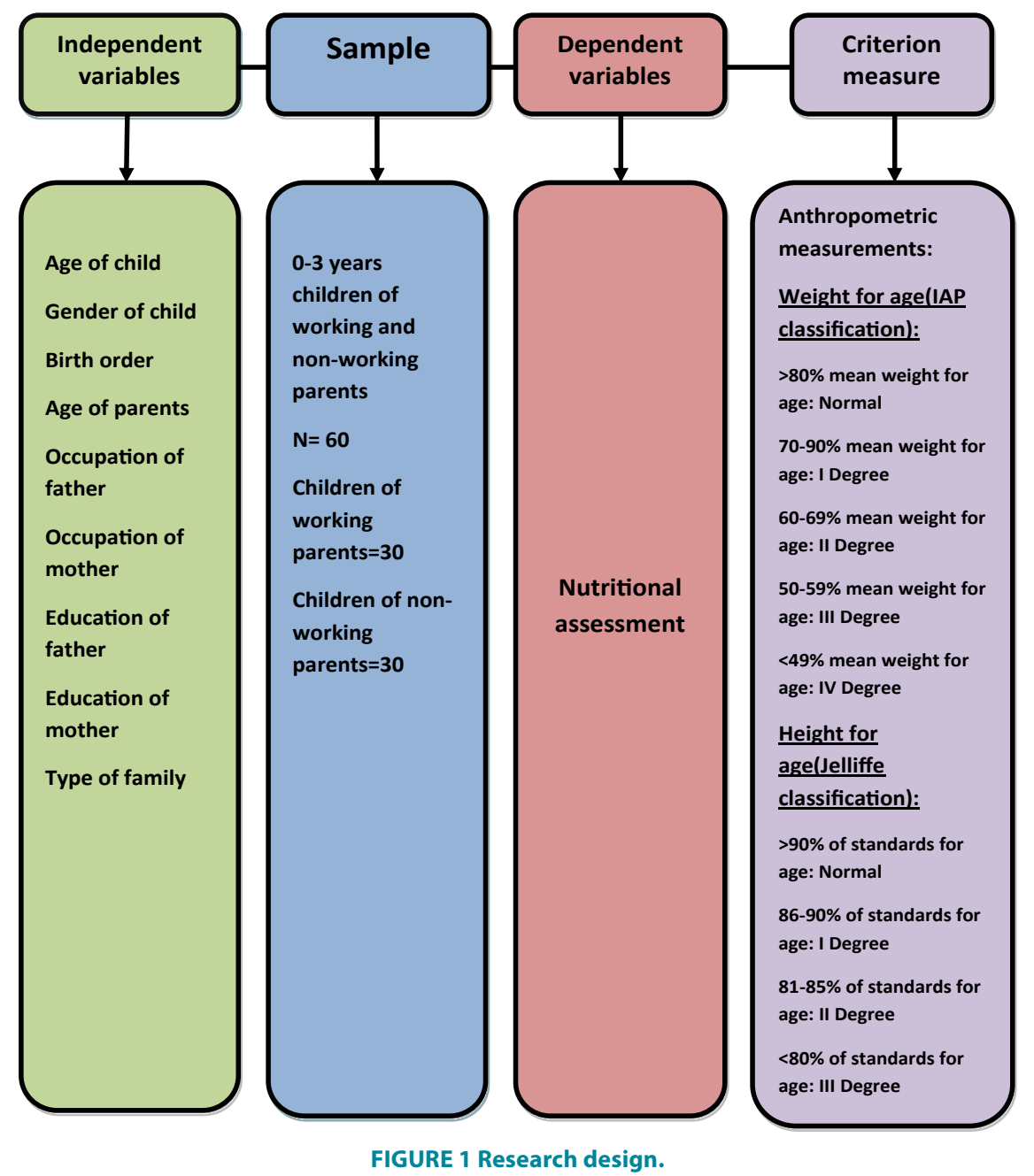

- $50-59 \%$ mean weight for age: III Degree(severe)

- $<49 \%$ mean weight for age: IV Degree(deficit)

\section{Height for age:}

Following four categories for height deficit were derived using Jelliffe classification:

- $>90 \%$ of the standards for age: Normal

- $86-90 \%$ of the standards for age: Grade I(Mild)

- $81-85 \%$ of the standards for age: Grade II(Moderate)

- $<80 \%$ of the standards for age: Grade III(poor)

The standards of WHO were used for referral value of height and weight.

\section{Description of tool}

The tool consisted of two parts as:

Part 1: Demographic variables

It comprises of 9 items for obtaining personal information i.e. age, gender, birth order, age of parents, occupation of father, occupation of mother, education of father, education of mother, type of family which are used to assess the baseline information.

Part 2: Anthropometric measurements and nutritional assessment criteria

It comprises of 2 items of anthropometric measures i.e. weight and height.

Nutritional assessment criteria involve 13 items. Each consists of one normal and two abnormal signs and each normal sign carries 0 and each abnormal carries 1 mark.

Scoring:-

- 0-4: Normal

- 5-11: I Grade (mild)

- 12-18: II Grade (moderate)

- 19-25: III Grade (severe)

\section{- Pilot Study}

Pilot study was conducted on March 2015 to 
ensure the reliability of tool and feasibility of the study. The sample size was taken 5 children of working women and 5 children of non-working women by purposive sampling technique.

\section{Result}

\section{- Section 1: Socio demographic characteristics:}

It shows that 0-3 years aged children of working and non-working women were distributed into various categories according to age(in year), gender, birth order, age of parents, occupation of father, occupation of mother, education of father, education of mother, type of family. According to age majority of children were in the age group of $2-3$ years $(50 \%)$ followed by age group $1-2$ years (30\%), 0-1 years (20\%). According to Gender majority of children were males $41(68.33 \%)$ followed by females 19 (31.66\%). According to birth order majority of children were having birth order $1(48.33 \%)$ followed by $2(41.66 \%), 3$ birth order (8.33), $>3$ birth order (1.66\%). According to age of parents majority of parents were in the age group of 2130 years $(71.66 \%)$ followed by age group $31-$ $40(26.66 \%),<20$ years $(1.66 \%)$. According to occupation of father maximum children's father fall in private job $(85 \%)$, followed by government $(8.33 \%)$, others $(5 \%)$, unemployed $(1.66 \%)$ [13]. According to occupation of mother maximum children's mother fall in housewife category (50\%), followed by private job (45\%), government $(5 \%)$ (TABLE 1). According to education of father maximum children's father fall in matric/senior secondary (56.66) followed by graduate/post graduate (36.66\%), primary/ middle $(23.33 \%)$. According to education mother maximum children's mothers fall in graduate/postgraduate $(46.66 \%)$, matric/senior secondary ( $45 \%)$, primary/middle (3.33\%), and illiterate (1.66\%). According to type of family majority of children were having joint family (51.66\%) followed by nuclear family (48.33\%). Hence, it was concluded that majority of children who were assessed for nutritional status were in the age group of 2-3 years and majority of them were males having 1 birth order and age of parents falls under 21-30 years whose occupation of father is private and mother is housewife and education of father is matric/ senior secondary and education of mother is graduate/post graduate and type of family is nuclear.

TABLE 2 depicts that according to weight for age, mean of children under normal category for non- working is 10.2 and for working is 11.12. Under I Degree for non-working are 10 and for working are 6. Under II Degree for working are 6.66. Under IV Degree for working are 5.3. Hence, it was concluded that majority of children with normal mean are of non-working

\begin{tabular}{|c|c|c|c|}
\hline Table 1. Nutritional assessment criteria were related to following aspects \\
\hline S.NO. & PARAMERETRS & ITEMS & MAX. SCORE \\
\hline 1. & General appearance & 3 & 2 \\
\hline 2. & Hair & 3 & 2 \\
\hline 3. & Face & 3 & 2 \\
\hline 4. & Eyes & 3 & 2 \\
\hline 5. & Lips & 3 & 2 \\
\hline 6. & Tongue & 3 & 2 \\
\hline 7. & Teeth & 3 & 2 \\
\hline 8. & Gums & 3 & 2 \\
\hline 9. & Glands & 3 & 2 \\
\hline 10. & Skin & 3 & 2 \\
\hline 11. & Nails & 2 & 1 \\
\hline 12. & Oedema & 3 & 2 \\
\hline 13. & Rachitic changes & 3 & \\
\hline
\end{tabular}

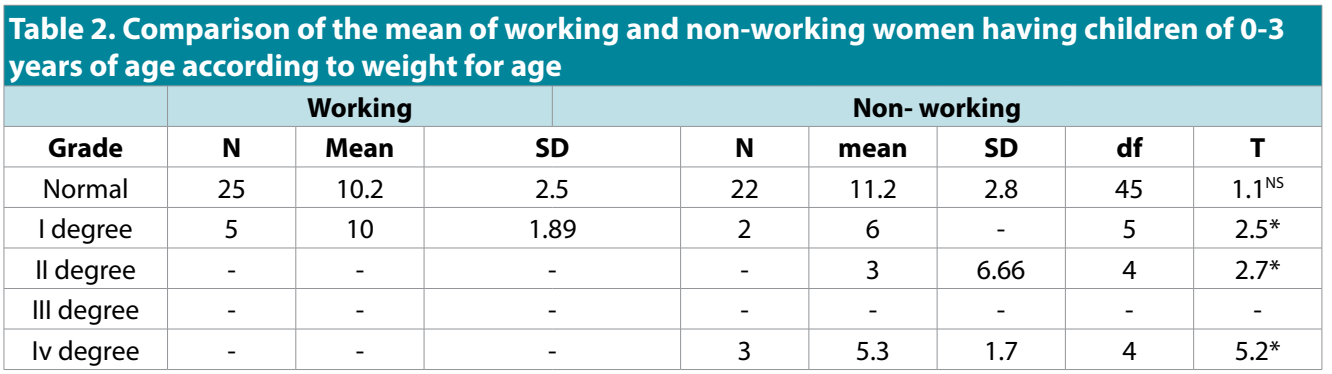

*significant, NS=non-significant, $\mathbf{n = 6 0}$ 
women (10.2) as compared to working women (11.12).

TABLE 3 depicts that according to height for age, mean of children under normal category for non- working is 79.6 and for working is 78 . Under I Degree for non-working are 83 and for working is 82 . Under II Degree for working are 72. Under III Degree for working are 72. Hence, it was concluded that majority of children with normal mean are of non-working women (79.6) as compared to working women (78).

TABLE 4 depicts that children of nonworking mother are $30(100 \%)$ had normal nutrition but children of working mother are 28(93.34\%) had normal nutrition [14]. Non- working mother have no child of I grade but working mother have 2 children $(6.66 \%)$ of mild category. Hence, it was revealed that nonworking mothers have (100\%) normal nutrition of their children but working mothers have (93.34\%) normal nutrition of children.

TABLE 5 depicts that according to weight for age age of child, $0-1$ year were $23.3 \%$ children of non-working women and $13.13 \%$ children of working women are followed by $1-2$ year were $26.6 \%$ children of non-working women and $6.66 \%$ children of working women followed by $2-3$ year were $33.33 \%$ children of non-working and $53.33 \%$ children of working women in normal degree. In I Degree age of child $3.33 \%$ children of non-working women

Table 3. Comparison of the mean of working and non-working women having children of 0-3 years of age according to height for age.

\begin{tabular}{|c|c|c|c|c|c|c|c|c|}
\hline & \multicolumn{9}{|c|}{ Working } & \multicolumn{7}{c|}{ Non-working } \\
\hline Grade & N & Mean & SD & N & mean & SD & df & T \\
\hline Normal & 28 & 79.6 & 10.4 & 17 & 78 & 15.8 & 43 & $0.23^{\text {NS }}$ \\
\hline I degree & 2 & 83 & 1.4 & 4 & 82 & 2.3 & 4 & $0.54^{*}$ \\
\hline II degree & - & - & - & 7 & 72 & 16.4 & 12 & $11.6^{*}$ \\
\hline III degree & - & - & - & 2 & 72 & 2.8 & 2 & 36 \\
\hline IV degree & - & - & - & 2 & 72 & 2.8 & 2 & $36^{*}$ \\
\hline
\end{tabular}

Table 4. Frequency and percentage distribution of children (0-3 years) among working and non-working mother according to the nutritional assessment criteria.

\begin{tabular}{|l|c|c|c|c|c|}
\hline \multicolumn{2}{|c|}{} & \multicolumn{2}{c|}{ Working } & \multicolumn{2}{c|}{ Non-working } \\
\hline Categories & Score & N & $\%$ & N & \% \\
\hline Normal & $0-4$ & 30 & 100 & 28 & 6.34 \\
\hline I grade (mild) & $5-11$ & - & - & - & - \\
\hline II grade (moderate) & $12-18$ & - & - & - & - \\
\hline III grade (severe) & $19-25$ & - & - & \\
\hline
\end{tabular}

Table 5. Frequency and percentage distribution of weight for age among working and nonworking women having children of 0-3 years of age according to age (in years).

\begin{tabular}{|c|c|c|c|c|c|}
\hline \multirow[b]{2}{*}{ Grades } & \multirow[b]{2}{*}{ Age (in years) } & \multicolumn{2}{|c|}{ Working } & \multicolumn{2}{|c|}{ Non-working } \\
\hline & & $\mathbf{F}$ & $\%$ & $\mathbf{F}$ & $\%$ \\
\hline \multirow{3}{*}{ Normal } & $0-1$ & 7 & 23.33 & 4 & 13.13 \\
\hline & $1-2$ & 8 & 26.66 & 2 & 6.66 \\
\hline & $2-3$ & 10 & 33.33 & 16 & 53.33 \\
\hline \multirow[t]{3}{*}{ I degree } & $0-1$ & 1 & 3.33 & 1 & 3.33 \\
\hline & $1-2$ & 2 & 6.66 & - & - \\
\hline & $2-3$ & 1 & 3.33 & - & - \\
\hline \multirow[t]{3}{*}{ Il degree } & $0-1$ & 1 & 3.33 & 2 & 6.66 \\
\hline & $1-2$ & - & - & - & - \\
\hline & $2-3$ & - & - & - & - \\
\hline \multirow[t]{3}{*}{ III degree } & $0-1$ & - & - & 1 & 3.33 \\
\hline & $1-2$ & - & - & - & - \\
\hline & $2-3$ & - & - & - & - \\
\hline \multirow[t]{3}{*}{ Iv degree } & $0-1$ & - & - & 2 & 6.66 \\
\hline & $1-2$ & - & - & - & - \\
\hline & $2-3$ & - & - & - & - \\
\hline
\end{tabular}


and working women followed by 1 - 2 year were $6.66 \%$ were children of non-working women and followed by 2-3year $3.33 \%$ were children of non-working women. In II Degree age of child 0-1 year, 3.33\% were children of non-working women and $6.66 \%$ children of working women followed by 2-3year were $3.33 \%$ children of working women. In III Degree age of child 0 -1year, $3.33 \%$ children of working women. In IV Degree age of child 0-1year, 6.66\% children of working women followed by age 2-3 years were $3.33 \%$ children of working women. Hence, it can be concluded that majority of children age group 2-3year fall under normal category but children of working women fall under normal and also under III Degree and IV Degree of malnutrition.

TABLE 6 depicts according to height for age that age of child, $0-1$ year were $26.6 \%$ children of non-working women and $20 \%$ children of working women are followed by 1-2 year were $33.33 \%$ children of non-working women and $3.33 \%$ children of working women followed by $2-3$ year were $33.33 \%$ children of non-working and $33.33 \%$ children of working women in normal degree. In I Degree age of child 3.33\% children of working women followed by 2-3 year were $6.66 \%$ were children of non-working women and $10 \%$ were children of non-working women. In II Degree age of child 0-1 year, 10\% were children of working women followed by $2-3$ year were $13 \%$ children of working women. In III Degree age of child 0-1year, 3.33\% children of working women followed by age 2-3 years were $3.33 \%$ children of working women [15]. Hence, it can be concluded that majority of children age group 1-2 and 2-3year fall under normal category but children of working women fall under normal and also under II Degree of malnutrition.

TABLE 7 depict that according to weight for age, $60 \%$ male child of non-working women and $53.33 \%$ male child of working women followed by female child of $23.33 \%$ of nonworking women and $20 \%$ were female child of working women in normal category. In I Degree, male and female child were $6.66 \%$ of non-working women and $3.33 \%$ were male and

\begin{tabular}{|c|c|c|c|c|c|}
\hline \multirow[b]{2}{*}{ Grades } & \multirow[b]{2}{*}{ Age (in years) } & \multicolumn{2}{|c|}{ Working } & \multicolumn{2}{|c|}{ Non-working } \\
\hline & & $\mathbf{F}$ & $\%$ & $\mathbf{F}$ & $\%$ \\
\hline \multirow{3}{*}{ Normal } & $0-1$ & 8 & 26.66 & 6 & 20 \\
\hline & $1-2$ & 10 & 33.33 & 1 & 3.33 \\
\hline & $2-3$ & 10 & 33.33 & 10 & 33.33 \\
\hline \multirow[t]{3}{*}{ I degree } & $0-1$ & - & - & - & - \\
\hline & $1-2$ & - & - & 1 & 3.33 \\
\hline & $2-3$ & 2 & 6.66 & 3 & 10 \\
\hline \multirow[t]{3}{*}{ II degree } & $0-1$ & - & - & 3 & 10 \\
\hline & $1-2$ & - & - & - & - \\
\hline & $2-3$ & - & - & 4 & 13 \\
\hline \multirow[t]{3}{*}{ III degree } & $0-1$ & - & - & 1 & 3.33 \\
\hline & $1-2$ & - & - & - & - \\
\hline & $2-3$ & - & - & 1 & 3.33 \\
\hline
\end{tabular}

\begin{tabular}{|c|c|c|c|c|c|}
\hline \multirow[b]{2}{*}{ Grades } & \multirow[b]{2}{*}{ Age (in years) } & \multicolumn{2}{|c|}{ Working } & \multicolumn{2}{|c|}{ Non-working } \\
\hline & & $\mathbf{F}$ & $\%$ & $\mathbf{F}$ & $\%$ \\
\hline \multirow{2}{*}{ Normal } & Male & 18 & 60 & 16 & 53.33 \\
\hline & Female & 7 & 23.33 & 6 & 20 \\
\hline \multirow{2}{*}{ I degree } & Male & 2 & 6.66 & 1 & 3.33 \\
\hline & Female & 2 & 6.66 & 1 & 3.33 \\
\hline \multirow{2}{*}{ II degree } & Male & 1 & 3.33 & 1 & 3.33 \\
\hline & Female & - & - & 2 & 6.66 \\
\hline \multirow{2}{*}{ III degree } & Male & - & - & - & - \\
\hline & Female & - & - & - & - \\
\hline \multirow{2}{*}{ IV degree } & Male & - & - & 10 & 10.00 \\
\hline & Female & - & - & - & - \\
\hline
\end{tabular}


female child of working women. In II Degree, male child were $3.33 \%$ of non-working women and $3.33 \%$ were male child of working women followed by female child were $6.66 \%$ were of working women. In IV Degree, male child were $10 \%$ of non-working women. Hence, it can be concluded that majority of normal child is male child in both working and non-working women.

TABLE 8 depict that according to height for age, $63.33 \%$ male child of non-working women and $33.33 \%$ of working women followed by female child of $30 \%$ of non-working women and $20 \%$ were female child of working women in normal category. In I Degree, male child were $3.33 \%$ of non-working and $16.66 \%$ were male child of working women followed by female child were $3.33 \%$ of non-working women. In II Degree, male child were $13.33 \%$ of working women followed by female child were $10 \%$ were of working women. In III Degree, male child were $6.66 \%$ of working women. Hence, it can be concluded that majority of normal height is of male child's in non-working and working women.

Frequency and percentage distribution of weight for age among working and nonworking women having children of 0-3 years of age according to birth order can be described as that according to weight for age, child birth order 1 were $36.6 \%$ children of non-working women and working women followed by birth order 2 were $36.6 \%$ were children of nonworking women and $26.66 \%$ were children of working women followed by birth order 3 were $10 \%$ children of non-working women and $6.66 \%$ were children of working women followed by birth order $>3$ were $3.33 \%$ children of working women under normal category. In I Degree, child birth order 1 were $6.66 \%$ children of nonworking women and $3.33 \%$ were children of working women followed by birth order 2 were $6.66 \%$ children of non-working women. In II Degree, child birth order 1 were $10 \%$ children of working women followed by birth order 2 were $3.33 \%$ children of non-working women. In III Degree, child birth orders 2 were $3.33 \%$ children of working women. In IV Degree, child birth order 1 were $3.33 \%$ children of working women followed by birth order 2 were $6.66 \%$ children of working women. Hence, it can be concluded that the majority of normal children fall under birth order 1 and 2 of non-working women and majority of child birth order 1 of working women fall under normal and II Degree of malnutrition.

Frequency and percentage distribution of height for age among working and nonworking women having children of 0-3 years of age according to birth order is reviewed as that according to height for age, child birth order 1 were $43.33 \%$ children of non-working women and $26.66 \%$ were children of working women followed by birth order 2 were $43.33 \%$ were children of non-working women and $23.33 \%$ were children of working women followed by birth order 3 were $6.66 \%$ children of nonworking women and $6.66 \%$ were children of working women followed by birth order $>3$ were $3.33 \%$ children of working women followed by birth order $>3$ were $3.33 \%$ children of working women fall under normal category. In I Degree, child birth order 1 were $10 \%$ children of working women followed by birth order 2 were $3.33 \%$ children of non-working women followed by birth order 3 were $3.33 \%$ children of non-working women and working women. In II Degree, child birth order 1 were $13 \%$ children of working women followed by birth order 2 were $10 \%$ children of working women. In III Degree, child birth order 1 and 2 were $3.33 \%$ children of working women. Hence, it can be concluded that the majority of normal children fall under birth order 1 and 2 of non-working women and majority of child birth order 1 of working women fall under normal and birth order 2 fall II Degree of malnutrition.

Frequency and percentage distribution of weight for age among working and nonworking women having children of 0-3 years of age according to age of parents (in years) describes that $<20$ were having $3.33 \%$ children in non-working followed by age $21-30$ years, in

Table 8. Frequency and percentage distribution of height for age among working and nonworking women having children of 0-3 years of age according to gender of child.

\begin{tabular}{|c|c|c|c|c|c|}
\hline \multirow{2}{*}{ Grades } & \multicolumn{2}{|c|}{ Working } & \multicolumn{2}{c|}{ Non-working } \\
\hline \multirow{2}{*}{ Normal } & Age (in years) & F & $\%$ & F & \% \\
\cline { 2 - 6 } & Male & 19 & 63.33 & 10 & 20 \\
\hline \multirow{2}{*}{ I degree } & Female & 9 & 30 & 6 & 16.66 \\
\hline \multirow{2}{*}{ II degree } & Male & 1 & 3.33 & 5 & - \\
\cline { 2 - 6 } & Female & 1 & 3.33 & - & 13.3 \\
\hline \multirow{2}{*}{ III degree } & Male & - & - & 4 & 10.0 \\
\cline { 2 - 6 } & Female & - & - & 3 & 6.66 \\
\hline
\end{tabular}


non-working, $40 \%$ in working followed by age $31-40$ years, $16.6 \%$ in non-working, $13.33 \%$ in working were normal. The age of parents 2130 years were having $13.33 \%$ children in non-working were under I degree. The age of parents $21-30$ years were having $10 \%$ children in working followed by age 31-40 years, $3.33 \%$ in non-working were under II degree. The age of parents 21-30 years were having 3.33\% children in working were under III degree. The age of parents 21-30 years were having $10 \%$ children in working under IV degree. Hence it can be concluded that children whose parent's age is $<20$ years have less normal percentage $(3.33 \%)$ but whose parent's age is $21-30$ have more normal nutrition of children having $63.33 \%$ of non-working women and $40 \%$ were children of working women.

Frequency and percentage distribution of height for age among working and nonworking women having children of 0-3 years of age according to age of parents (in years) depicts that according to height for age, Age of parents (in years), <20 were having 3.33\% children in non-working followed by age 21-30 years, $76.66 \%$ non-working, $40 \%$ in working followed by $31-40$ years, $13.33 \%$ in nonworking, $16.66 \%$ in working were Normal. The age of parents 21-30 years were having 3.33\% children in working followed by age $31-40$ years, $6.66 \%$ in non-working, $10 \%$ in working were under I Degree. The age of parents 21-30 years were having $16.66 \%$ children in working followed by age $31-40$ years, $6.66 \%$ in working were under II Degree. The age of parents 21-30 years were having $6.66 \%$ children in working were under III Degree. Hence, it can be concluded that Children whose parent's age is $<20$ year have less normal percentage $(3.33 \%)$ but whose parent's age is 21-30 have more normal nutrition of children having $76.66 \%$ of Non-working women and $40 \%$ were children of working women.

Frequency and percentage distribution of weight for age among working and nonworking women having children of 0-3 years of age according to occupation of father described that according to weight for age, (occupation of father) In normal degree 73.3\% fathers are on private job, $10 \%$ have other job of children among non-working women and $3.33 \%$ fathers are unemployed, $3.33 \%$ have govt. job, $56.6 \%$ have private job of children among working women. In I degree $13.3 \%$ fathers are on private job of children among nonworking women and $3.33 \%$ have private job of children among working women. In II degree $3.33 \%$ fathers are on private job of children among non-working women and 10\% have private job of children among working women.
In III degree $3.33 \%$ fathers are on private job of children among working women. In IV degree $3.33 \%$ fathers are on govt. job and $6.66 \%$ on private job of children among working women. Hence, it can be concluded that mostly the fathers of children falling in normal category among non-working women are on private job and majority of children who fall in IV degree, their fathers are having neither government job nor private job.

Frequency and percentage distribution of height for age among working and nonworking women having children of 0-3 years of age according to occupation of father showed that according to height for age, (occupation of father). In normal degree $86.6 \%$ fathers are on private job, $6.6 \%$ have other job of children among non-working women and $3.33 \%$ fathers are unemployed, $10 \%$ have govt. job, $43.3 \%$ have private job of children among working women. In I degree $3.33 \%$ fathers are on private job and $3.33 \%$ are on any other job of children among non-working women and $13.33 \%$ have private job of children among working women. In II degree $6.66 \%$ fathers are on government job and $16.66 \%$ are on private job of children among working women. In III degree $6.66 \%$ fathers are on private job of children among working women. Hence it can be concluded that majority of normal children fall under category in which fathers are on private job among non-working women and the majority of children in III degree fall under the category in which fathers are on private job among children of working women.

Frequency and percentage distribution of weight for age among working and nonworking women having children of 0-3 years of age according to occupation of mother concluded that according to weight for age, (occupation of mother) In normal degree 83.3\% mothers are housewives of children among nonworking women and 10\% mothers have govt. job, $63.3 \%$ have private job of children among working women. In I degree $13.3 \%$ mothers are housewives of children among non-working women and $3.33 \%$ have private job of children among working women. In II degree 3.33\% mothers are housewives of children among nonworking women and 10\% have government job of children among working women. In III degree $3.33 \%$ mothers are on private job of children among working women. In IV degree $3.33 \%$ mothers are on govt. job and $6.66 \%$ on private job of children among working women. Hence it can be concluded that majority of children under normal category are having their 
mothers as housewives and least children in IV degree are falling under the category whose mothers are on govt. job.

Frequency and percentage distribution of height for age among working and nonworking women having children of 0-3 years of age according to occupation of mother states that according to height for age, (occupation of mother) In normal degree $93.3 \%$ mothers are housewives of children among non-working women and $6.66 \%$ have govt. job, $50 \%$ have private job of children among working women. In I degree $6.66 \%$ mothers are housewives of children among non-working women and $13.33 \%$ have private job of children among working women. In II degree 3.33\% mothers are housewives among non-working women and $3.33 \%$ are on government job and $20 \%$ on private job of children among working women. In III degree $6.66 \%$ mothers are on private job of children among working women. Hence it can be concluded that majority of children under normal category are having their mothers as housewives and least children in IV degree are falling under the category whose mothers are on govt. job.

Frequency and percentage distribution of weight for age among working and nonworking women having children of 0-3 years of age according to education of father depicts that according to weight for age, (education of father) In normal degree $6.66 \%$ fathers have primary/middle education, $53.3 \%$ have matric/ senior sec education and $23.3 \%$ have done grad/ PG of children among non-working women and $3.33 \%$ fathers have primary/middle education, $33.3 \%$ have matric/senior sec education, $36.6 \%$ have done grad/PG of children among working women. In I degree $10 \%$ fathers have done matric/senior sec and 3.33\% have grad/ PG education of children among non-working women and $3.33 \%$ fathers have done matricl senior sec education of children among working women. In II degree $3.33 \%$ fathers have done $\mathrm{grad} / \mathrm{PG}$ of children among non-working women and $3.33 \%$ of fathers have done grad/ PG of children among working women. In III degree $3.33 \%$ fathers have done matric/senior sec education of children among working women. In IV degree $10 \%$ have done matric/senior sec education of children among working women. Hence it can be concluded that majority of the normal children fall under the category whose fathers are matric/senior secondary educated among non-working mothers and majority of the children of IV degree fall under the category whose fathers are matric/senior secondary educated among working women.
Frequency and percentage distribution of height for age among working and nonworking women having children of 0-3 years of age according to education of father illustrate that according to height for age, (education of father) In normal degree $6.66 \%$ fathers have primary/middle education, $60 \%$ have matric/senior sec and $26.6 \%$ have grad/ PG education of children among non-working women and $23.3 \%$ fathers have matric/senior sec and $33.3 \%$ have grad/PG education of children among working women. In I degree $3.33 \%$ fathers have done matric/senior sec and 3.335 have done grad/PG education of children among non-working women and $3.33 \%$ have done primary/middle, $6.66 \%$ have done matric/ senior sec and $3.33 \%$ have done $\operatorname{grad} / \mathrm{PG}$ education of children among working women. In II degree $3.33 \%$ fathers have done primary/ middle, $20 \%$ have done matric/senior sec and $3.33 \%$ have done grad/PG education of children among working women. In III degree $3.33 \%$ fathers have done primary/middle, $3.33 \%$ fathers have done matric/senior sec education of children among working women. Hence it can be concluded that majority of the children of normal fall under the category whose fathers are matric/senior secondary educated among nonworking women and majority of children of III degree are fall under category whose fathers are primary/middle and matric/senior secondary educated among working women.

Frequency and percentage distribution of weight for age among working and nonworking women having children of 0-3 years of age according to education of mother describes that according to weight for age, (education of mother) In normal degree 3.3\% mothers are illiterate, $10 \%$ primary/secondary and 50\% matric/senior sec and 20\% grad/PG of children among non-working women and $26.6 \%$ mothers are matric/senior sec, $46.6 \%$ $\mathrm{grad} / \mathrm{PG}$ of children among working women. In I degree $3.3 \%$ mothers are educated up to primary/middle, $6.6 \%$ matric/senior sec, 3.3\% $\mathrm{grad} / \mathrm{PG}$ of children among non-working women and $3.33 \%$ matric/senior sec of children among working women. In II degree $3.33 \%$ mothers are grad/PG of children among nonworking women and $3.3 \%$ primary $/$ middle and $3.3 \%$ matric/senior, $6.6 \%$ are $\mathrm{grad} / \mathrm{PG}$ of children among working women. In III degree $3.33 \%$ matric/senior sec and 3.3\% are grad/ PG of children among working women. In IV degree 3.33\% mothers are matric/senior sec and $6.6 \%$ are grad/PG of children among working women. Hence, it can be concluded that mostly the children of normal category fall under the category whose mothers are matric/senior secondary educated among non- 
working women and majority of the children of IV degree fall under category whose mothers are matric/senior secondary educated among working women.

Frequency and percentage distribution of height for age among working and nonworking women having children of 0-3 years of age according to education of mother shows that according to height for age, (education of mother) In normal degree 3.3\% are illiterate mothers, and $13.3 \%$ primary/middle, $50 \%$ matric/senior sec, $26.6 \%$ grad/PG of children among non-working women and $13.3 \%$ are matric/senior educated, $43.3 \%$ are grad/PG of children among working women. In I degree $3.3 \%$ mothers are matric/senior sec educated, $3.3 \%$ mothers are grad/PG of children among non-working women and $10 \%$ mothers are primary/middle of children among working women. In II degree $16.6 \%$ mothers are matricl senior sec educated, $6.6 \%$ are $\mathrm{grad} / \mathrm{PG}$ of children among working women. In III degree $6.6 \%$ mothers are matric/senior sec educated of children among working women. Hence, it can be concluded that majority of the children of normal degree are falling under the category whose mothers are matric/senior secondary educated among non-working women and majority of children of III degree are falling under category whose mothers are matric/senior secondary educated among working women.

Frequency and percentage distribution of weight for age among working and nonworking women having children of 0-3 years of age according to type of family concluded that according to weight for age, $33.33 \%$ belong to nuclear family and $50 \%$ belong to joint family in non-working and $43.33 \%$ to nuclear and $30 \%$ to joint in working were normal. Children belong to joint $13.33 \%$ in nonworking and $3.33 \%$ to nuclear in working were under I Degree. Children belong to joint 3.33\% in non-working and $3.33 \%$ in nuclear, $6.66 \%$ in joint in working were under II Degree. Children belong to nuclear $3.33 \%$ in working were under III Degree. Children belong to nuclear 10\% in working under IV Degree. Hence, it can be concluded that majority of children of normal category belong to joint family in non-working and nuclear family in working. Under IV Degree majority of children belong to nuclear family in working.

Frequency and percentage distribution of height for age among working and nonworking women having children of $0-3$ years of age according to type of family shows that according to height for age, 30\% belong to nuclear family and $63.33 \%$ belong to joint family in non-working and $26.66 \%$ to nuclear and $30 \%$ to joint in working were normal. Children belong to nuclear 3.33\%, $3.33 \%$ to joint in non-working and $10 \%$ to nuclear, $3.33 \%$ to joint in working were under I Degree. Children belong to $23.33 \%$ in nuclear in working were under II Degree. Children belong to $3.33 \%$ to nuclear, $3.33 \%$ to joint in working were under III Degree. Hence, it can be concluded that majority of children of normal category belong to joint family in nonworking and nuclear family in working. Under III Degree the majority of children are same in nuclear and joint family in working.

\section{Objective: major findings:}

According to demographic variables:

Hence, it was concluded that majority of children who were assessed for nutritional status were in the age group of 2-3 years and majority of them were males having 1 birth order and age of parents falls under 21-30 years whose occupation of father is private and mother is housewife and education of father is matric/ senior secondary and education of mother is graduate/post graduate and type of family is nuclear.

According to first objective to compare the nutritional status of children (0-3years) of working and non-working parents

- Comparison according to weight for age majority of children with normal mean is of non-working women (10.2) as compared to working women (11.12).

- Comparison according to height for age majority of children with normal mean is of non-working women (79.6) as compared to working women (78).

- Comparison among non-working mothers has (100\%) normal nutrition of their children but working mothers have (93.34\%) normal nutrition of children.

According to second objective to find out relationships between nutritional status and demographic variables such as age, gender, birth order, age of parents, occupation of mother and father, education of father and mother and type of family

- Children of age group 2-3 years have majority of normal children of non-working women and working women, $33.33 \%$ and $53.33 \%$ respectively. Hence, it can be concluded that majority of children age group 2-3year fall under normal category but children of working women fall under normal and also under III Degree and IV Degree of malnutrition.

- Children of non-working women have $60 \%$ normal male child and $53.3 \%$ male 
children of working women but normal female child have $23.3 \%$ of non-working women and $20 \%$ were female child of working women. Only $3.33 \%$ are male child who fall under II Degree of malnutrition but $6.66 \%$ are female child. Hence, it can be concluded that majority of normal child is of male child in non-working and working women and gender affect the nutrition of child.

- Children of birth order 1 have $36.66 \%$ in both working women and non-working women who fall under normal category and also birth order 2 have $36.66 \%$ children. Hence, it can be concluded that the majority of normal children fall under birth order 1 and 2 of nonworking women and majority of child birth order 1 of working women fall under normal and had less effect on nutrition of children regarding birth order.

- Children whose parent's age is $<20$ year have less normal percentage $(3.33 \%)$ but whose parent's age is $21-30$ have more normal nutrition of children having $63.33 \%$ of Nonworking women and $40 \%$ were children of working women. Hence it can be concluded that majority of normal children are of those parents who have age group 21-30 years and had effect on nutritional status of children of early marriage.

- Children whose father have private jobs have majority of normal $73.3 \%$ and other such as farming have $10 \%$ normal nutrition of children and $56.6 \%$ have normal nutrition of children whose parents are working women. Hence it can be concluded that whose father have private jobs have majority of normal children and only $3.33 \%$ were normal children whose father is unemployed and so occupation of father had affect the nutrition of children.

- Children whose mothers are housewife have majority of normal children $83.3 \%$ and $56.6 \%$ have normal nutrition of children whose mother is working women. Hence it can be concluded that whose mother is housewife have majority of normal children and also $3.33 \%$ and $10 \%$ were children whose mother have private jobs and so occupation of mother had affect the nutrition of children.

- Children whose fathers are matric/ senior secondary have majority of normal children (53.33\%) among non-working women and whose father are graduate/post graduated have majority of $36.66 \%$ children. Hence it can be concluded that majority of normal children are those whose father are educated as no normal child have illiterate father.

- Children whose mother are matric/ senior secondary have majority of normal children (50\%) among non-working women and whose mother are graduate/post graduated have majority of $46.66 \%$ normal children. Hence it can be concluded that majority of normal children are those whose mother are educated and parent's literacy affect the nutrition of children.

\section{Discussion}

In this chapter an attempt has been made to discuss the findings of the study in accordance with objectives of the research, to compare the nutritional assessment among working and non-working parents. The main purpose of the study was to assess the nutritional status of 0-3 years children among working and non-working women and compare the nutritional status among both and to find out relation between them and to provide guidelines to working and non-working women.

\section{Objectives \\ To compare the nutritional status of children (0-3years) of working and non-working parents.}

Majority of non-working mothers has $(100 \%)$ normal nutrition of their children but working mothers have (93.34\%) normal nutrition of children. The findings are supported by study conducted by (Krishna C Paudel, March 2006) which showed almost (77\%) children of non-working mothers had normal nutritional status.

\section{To find out relation between} nutritional status and selected variable such as age of child, gender, birth order, age of parents, occupation of mother and father, education of mother and father and type of family.

Majority of children who were assessed for nutritional status were in the age group of 2-3 years and majority of them were males having 1 birth order and age of parents falls under 2130 years whose occupation of father is private and mother is housewife and education of father is matric/senior secondary and education of mother is graduate/post graduate and type of family is nuclear. These findings are supported by the study conducted by (Sanghita Das, 2014) which revealed that majority of children with normal nutritional status were males and their parents were educated up to graduate level and they lived in nuclear family.

\section{Summary}

The present study was conducted to compare 
nutritional status of children (0-3 year) among working and non-working mother in Daba village, Ludhiana, Punjab. A study approach was used in study using sample random sampling method. 30 children of non-working women and 30 children of working women data was collected with the help of anthropometric measurement and nutritional assessment criteria. Tool was modified and tested for validity and reliability. Pilot study was conducted in the march, 2015.

\section{Conclusion}

The present study conducted by the researcher to assess the nutritional status of children (0-3year) among working women and non-working women revealed that majority of children among non-working women were normal and mother's employment leads to 93.3\% normal children and $6.67 \%$ fall under grade I i.e. is mild degree of malnutrition.

\section{Limitations}

The study is limited up to 60 children of Daba village, Ludhiana, Punjab.

\section{Recommendations}

Based on the findings of study, following recommendations are:

- A study can be conducted to assess the Mother's literacy and its effects on children nutritional status.

- The similar study may be conducted on a large sample to validate and generalize findings. 


\section{REFERENCES}

Alvaro T, Barbra B. Biodiversity and nutrition: A common path toward global food security and sustainable development. J. Food Comp. Analysis 19(7), 477-483 (2006).

Müller O, Krawinkel M. Malnutrition and health in developing countries. Can. Med. Assoc. J. 173(3),279-286 (2005).

Park K. Textbook of preventive and social medicine. $20^{\text {th }}$ edition, pp-455 (2009).

India Infoline news service: 1 in every 3 malnourished children in the world lives in India; 2010.

Rodríguez L, Cervantes E, Ortiz R. Malnutrition and Gastrointestinal and Respiratory Infections in Children: A
Public Health Problem. Int. J. Environ. Res. Public Health 8, 1174-1205 (2011).

http;//www.saudigastro.com.

http;//www.sarkartal.com/indianews.

Maini K, Ranchal P. Study the Nutritional Status of Primary School Children (510 Years) in Gurdaspur District. New Ind. J. Surg. 3(3); 172 (2012).

Devi L. Child development an introduction; encyclopedia of child and family welfare series 1-16.

Basu, Malwade A, Basu K. Women's economic roles and child survival: the case of India. Health Transition Rev. 1(1), 0 (1991).

Desai S, Jain D. Maternal employment and changes in family dynamics: the social context of women's work in rural South India. Population Dev. Rev. 20(1), 115-136 (1994).

Shams B, Golshiri P. Presenting a model for improvement of nutrition and growth promotion of children by the CIPP Evaluation model in Isfahan. Iran J. Pediatr. 15,221-228 (2005).

Basu AM, Basu K. Women's economic roles and the child survival. The case of India. Health Transition Rev. 1,1-20 (1991).

American Journal of Human Biology. 18(2),169-18 (2006).

Asthon D. Food advertising and childhood obesity. J. R. Soc. Med. 97(2),51-52 (2004). 